\title{
A Comprehensive Method for Calculating Impact of Coal Dust on the Marine Environment
}

\author{
YAO Wenwei ${ }^{1, a}$, YING Chao ${ }^{1, b}$ and ZHAO Xin ${ }^{1, c}$ \\ ${ }^{1}$ Zhejiang Institute of Hydraulics \& Estuary, Hangzhou, China \\ awwyao230@163.com, ${ }^{b} 28447353 @ q q . c o m z h a o,{ }^{c}$ 3989373@qq.com
}

\section{Keywords: coal wharf, coal dust, particle tracking}

Abstract. The coal dust will cause pollution of the marine environment when the coal wharf of a coastal power plant is operated. The coal loss in the process of unloading in the wharf was estimated through the standard formula, and then the amount of coal dust into the sea was determined. By the combined force of gravity and wind, the coal dust would land on the surface of the sea, the horizontal distance of the landing point and the coal wharf can be calculated by the empirical formula, then the source range of coal dust into the sea was generalized. The Lagrangian particle tracking method was used in the calculation of the diffusion process of the suspended coal particles, The concentration range of suspended coal particles was obtained.

\section{Introduction}

Coal is the most important part in China's energy structure, the total amount of coal consumption accounted for about 64\%[1] of total energy consumption in 2015. In order to facilitate the transport of coal, China's large-scale coal-fired power plants are mainly concentrated in the eastern coastal areas, almost all these power plants have built large dedicated coal wharf, the unloading process of coal from ship to the coal yard was often accompanied by dust, previous studies have focused on the atmospheric environment impact caused by dust [2,3], however coal dust is also a pollution source to the marine environment, dust from wharf to sea to eventually deposited in the seabed will have an impact on water quality and sediment quality. Therefore, a coastal coal power plant in Zhejiang province was studied as a case, the suspended and diffusion process was studied by the combining use of empirical formula and numerical simulation method, and the result can provide a reference for assessing the impact of coal dust on the marine environment.

Calculation of Coal Dust into Sea. Coal particles whose size less than $200 \mu \mathrm{m}$ was produced in the unloading and stacking process of coal, and those particle was likely to be raised under the action of mechanical action of wind and other effects, quantity of dust was mainly related to wind speed, moisture content of the coal and the unloading height, it can be estimated by the following formula[4]:

$$
\mathrm{Q}=0.03 \mathrm{~V}^{1.6} \mathrm{H}^{1.23} \mathrm{e}^{-0.28 \mathrm{~W}}
$$

Where $\mathrm{Q}$ is the amount of dust $(\mathrm{kg} / \mathrm{t}) ; \mathrm{V}$ is the actual wind speed $(\mathrm{m} / \mathrm{s}) ; \mathrm{W}$ is the coal moisture content $(\%) ; \mathrm{H}$ is the loading and unloading height $(\mathrm{m})$. The annual average wind speed near the project area was about $5.0 \mathrm{~m} / \mathrm{s}$; the moisture content of coal when it arrive at the wharf was about $8-10 \%$, for a negative side, we take $8 \%$; the height of the grab unloader operation was about $1 \sim 3 \mathrm{~m}$, for a negative side, $3 \mathrm{~m}$ was taken. Then $\mathrm{Q}$ can be estimated as $0.18 \mathrm{~kg} / \mathrm{T}$.

The coal wharf was composed of two 35,000-ton berths, equipped with four bridge type grab ship unloaders, nominal production rate of two of which was $1600 \mathrm{t} / \mathrm{h}$, the other two was $1500 \mathrm{t} / \mathrm{h}$. The maximum loading and unloading coal per hour was $6200 \mathrm{t}$, it all means the maximum loss $1102.5 \mathrm{~kg} / \mathrm{h}$.

Table 1. The percentage of typical coal dust in different size particle distribution

\begin{tabular}{lcccccccc}
\hline Particle size $(\mu \mathrm{m})$ & $0-10$ & $10-30$ & $30-50$ & $50-70$ & $70-90$ & $90-100$ & $100-200$ & $>200$ \\
\hline Percentage $(\%)$ & 2.2 & 4.5 & 4.4 & 3.5 & 4.3 & 2.1 & 21 & 20 \\
\hline
\end{tabular}


Table 1 are typical percentage of coal dust of different particle size distribution, the particle size of less than $200 \mu \mathrm{m}$ content in $42 \%$ in the total quantity of dust in the unloading operation, the density of coal dust is about $1.38 \mathrm{~g} / \mathrm{cm}^{3}$. When the grab unloaders are unloading the coal, a reflection plate which can suppress the dust through spraying is set surrounding the feeding funnel and the dust suppression efficiency is about $85 \%$ [5], the source of coal dust into the sea to be suspended can be calculated by the above date, and the source is $0.0193 \mathrm{~kg} / \mathrm{s}$.

\section{Numerical Model.}

2-D Hydrodynamic Module. The model is based on the solution of 2-D incompressible Reynolds averaged Navier-Stokes equations. Integration of the horizontal momentum equations and the continuity equation over depth the following 2-D shallow water equations are obtained[6]:

$$
\begin{aligned}
\frac{\partial \mathrm{h}}{\partial \mathrm{t}}+\frac{\partial h \bar{u}}{\partial \mathrm{x}}+\frac{\partial h \bar{v}^{\prime}}{\partial \mathrm{y}}= & h S \\
\frac{\partial h \bar{u}}{\partial t}+\frac{\partial h \bar{u}^{2}}{\partial x}+\frac{\partial h \overline{v u}}{\partial y}= & f \bar{v} h-g h \frac{\partial \eta}{\partial x}-\frac{h}{\rho_{0}} \frac{\partial p_{a}}{\partial x}-\frac{g h^{2}}{2 \rho_{0}} \frac{\partial \rho}{\partial x}+\frac{\tau_{s x}}{\rho_{0}}-\frac{\tau_{b x}}{\rho_{0}}- \\
& +\frac{\partial}{\partial x}\left(h T_{x x}\right)+\frac{\partial}{\partial y}\left(h T_{x y}\right)+h u_{s} s \\
\frac{\partial h \bar{v}}{\partial t}+\frac{\partial h \overline{u v}}{\partial x}+\frac{\partial h \bar{u}^{2}}{\partial y}= & -f \bar{u} h-g h \frac{\partial \eta}{\partial y}-\frac{h}{\rho_{0}} \frac{\partial p_{a}}{\partial y}-\frac{g h^{2}}{2 \rho_{0}} \frac{\partial \rho}{\partial y}+\frac{\tau_{s y}}{\rho_{0}}-\frac{\tau_{b y}}{\rho_{0}}- \\
& +\frac{\partial}{\partial x}\left(h T_{x y}\right)+\frac{\partial}{\partial y}\left(h T_{y y}\right)+h v_{s} s
\end{aligned}
$$

Where: $\mathrm{t}$ is the time; $\mathrm{x}, \mathrm{y}$ are the Cartesian co-ordinates; $\eta$ is the surface elevation; $\mathrm{d}$ is the still water depth; $\mathrm{h}=\mathrm{\eta}+\mathrm{d}$ is the total water depth; $u 、 v$ are the velocity components in the $x, y$ direction; $\mathrm{f}=2$ $\Omega \sin \Phi$ is the Coriolis parameter( $\Omega$ is the angular rate of revolution and $\Phi$ the geographic latitude) $\mathrm{g}$ is the gravitational acceleration; $\rho$ is the density of water; $\rho_{0}$ is the reference density of water; the lateral stresses $\mathrm{T}_{\mathrm{ij}}$ include viscous friction, turbulent friction and differential advection.

Particle Tracking Module. In the Particle Tracking Module a Lagrangian discrete-parcel method is used, the coal dust is represented by a large ensemble of small parcels. Every particle's transportation is governed in a random walk model. The position $\mathrm{x}(\mathrm{t})$ of each particle in a random walk model is described by the non-linear Langevin equation[7]:

$$
\frac{d^{\prime} x}{d t}=A(\stackrel{r}{x}, t)+B(\stackrel{r}{x}, t) \xi(t)
$$

Where $\mathrm{A}(\mathrm{x}, \mathrm{t})$ is a known vector representing the deterministic forces that act to change $x(t), B(x, t)$ is a known tensor that characterizes the random forces, and $\xi(\mathrm{t})$ is a vector composed of random numbers that represent the random nature of tidal mixing which, when averaged over sufficiently long time and space scales, becomes effectively random.

Eq.5 becomes equivalent to the stochastic differential equation

$$
d^{\prime} x=A\left(x^{\prime}(t), t\right) d t+B\left(x^{\prime}(t), t\right) d W(t)
$$

Where $\mathrm{dW}(\mathrm{t})$ is the random Wiener process. The mean value of $\mathrm{dW}(\mathrm{t})$ is zero and the mean square is proportional to $d t$. The simplest discretization of Eq.6 is the explicit Euler scheme for stochastic differential equations.

$$
\Delta \stackrel{r}{x}=\stackrel{r}{x}_{n}-\stackrel{r}{x}_{n-1}=A\left(\stackrel{r}{x}_{n-1}, t_{n-1}\right) \Delta t+B\left(\stackrel{r}{x}_{n-1}, t_{n-1}\right) \sqrt{\Delta t} Z_{n}
$$

Where $Z_{n}$ is vector of one, two, or three independent random numbers depending on the dimensionality of the problem form a distribution with zero mean and unit variance. 
In the limit when the number of particles is infinite and the time step is infinitely small, Eq.7 is equivalent to the Fokker-Planck equation:

$$
\frac{\partial f}{\partial t}+\frac{\partial}{\partial x_{i}}\left(A_{i} f\right)=\frac{\partial^{2}}{\partial x_{i} x_{j}}\left(\frac{1}{2} B_{i k} B_{j k} f\right)
$$

Where $f\left(x, t||_{0}^{I}, t_{0}\right)$ is the conditional probability density function.

\section{Model Parameters.}

The Range of Coal Dust into Sea. Once the coal dust particle was raised, it drift under the effect of wind, and gradually settle to the ground or sea surface due to its own gravity, the distance between the starting point to the fall point is the drift distance in the air medium. The settling velocity of the coal dust particle in the air can be estimated by the Stokes settling velocity formula[8]:

$$
V_{g}=\frac{d_{i}^{2} \rho g}{18 \mu}
$$

Where $V_{g}$ is the settling velocity of a coal particle; $\mathrm{d}_{i}$ is diameter of particle $(\mathrm{m}) ; \rho$ is the density of coal $\left(\mathrm{kg} / \mathrm{m}^{3}\right) ; g$ is the gravitational acceleration $\left(\mathrm{m} / \mathrm{s}^{2}\right) ; u$ is the dynamic viscosity of air $(\mathrm{Pa} \bullet \mathrm{s})$. According to the model proposed by Walker[9]: coal dust particle do linear motion to the surface of the sea by the combined action of mean wind velocity $V_{w}$ and settling velocity $V_{g}$, it is assumed that coal particle to do straight trajectory with average inclination angle $\operatorname{tg}^{-1}\left(\mathrm{v}_{\mathrm{g}} \mathrm{v}_{\mathrm{w}}^{-1}\right)$ [10] in normal distribution:

$$
\Phi=\operatorname{tg}^{-1}\left(H \cdot X^{-1}\right)-\operatorname{tg}^{-1}\left(V_{g} \cdot V_{w}^{-1}\right) \approx H \cdot X^{-1}-V_{g} \cdot V_{w}^{-1}
$$

Where, $H$ is the height of particle source; $X$ is horizontal distance of coal particles moving in the air. When the deviation angle $\Phi=0$,

$$
X=H \cdot V_{w} \cdot V_{g}^{-1}
$$

According to the above formulas, the horizontal distance $X$ can be estimated. Table 2 is the settling velocity of particles with different diameters and horizontal distances of particles moving in the air for those different size particles.

Table 2. Settling velocity of particles and its horizontal distances of particles moving in the air

\begin{tabular}{ccccccc}
\hline Diameter & Settling & \multicolumn{5}{c}{ Wind scale /typical wind speed $(\mathrm{m} / \mathrm{s})$} \\
\cline { 3 - 6 }$(\mu \mathrm{m})$ & velocity $(\mathrm{m} / \mathrm{s})$ & $2 / 2.5$ & $3 / 4.3$ & $4 / 6.8$ & $5 / 8.5$ & $6 / 12.5$ \\
\hline$<20$ & 0.012 & 3125 & 5375 & 8500 & 10625 & 15625 \\
$20-60$ & 0.109 & 344 & 592 & 936 & 1170 & 1720 \\
$60-100$ & 0.284 & 132 & 227 & 359 & 441 & 660 \\
$100-150$ & 0.556 & 67 & 116 & 183 & 229 & 337 \\
$150-200$ & 0.833 & 45 & 77 & 122 & 153 & 225 \\
$>200$ & 1.667 & 22 & 39 & 61 & 76 & 112 \\
\hline
\end{tabular}

The smaller the particle size and the greater the wind speed,the farther the horizontal distance. The particle whose diameter less than $20 \mu \mathrm{m}$ can move $3.1 \mathrm{~km}$ from the wharf until settle on the sea surface under the constant wind speed $2.5 \mathrm{~m} / \mathrm{s}$, while under strong wind $(12.5 \mathrm{~m} / \mathrm{s})$, the distance is about $15 \mathrm{~km}$, however because of the smaller proportion of this scale coal dust, the generalized of source position in the numerical model of these particle will not be considered.

According to the measured wind data statistics, the annual average wind speed is about $5.0 \mathrm{~m} / \mathrm{s}$, taking wind scale 3 and $100 \mu \mathrm{m}$ for characterizing the wind speed and the particle size respectively, the distance can be estimated as about $200 \mathrm{~m}$. The source position of the coal particles can be generalized as a circle whose radius is $200 \mathrm{~m}$ and the center of the circle is the center of the wharf. Because of the different size of particles, the source positions are set in 80 points, which located in 
four circles and their radius is $50 \mathrm{~m}, 100 \mathrm{~m}, 150 \mathrm{~m}$ and $200 \mathrm{~m}$ respectively, each circle aliquot taken 20 points, the position of these points is showed in Fig.1. It is assumed that the coal dust into the sea uniform distribution in the 80 points.

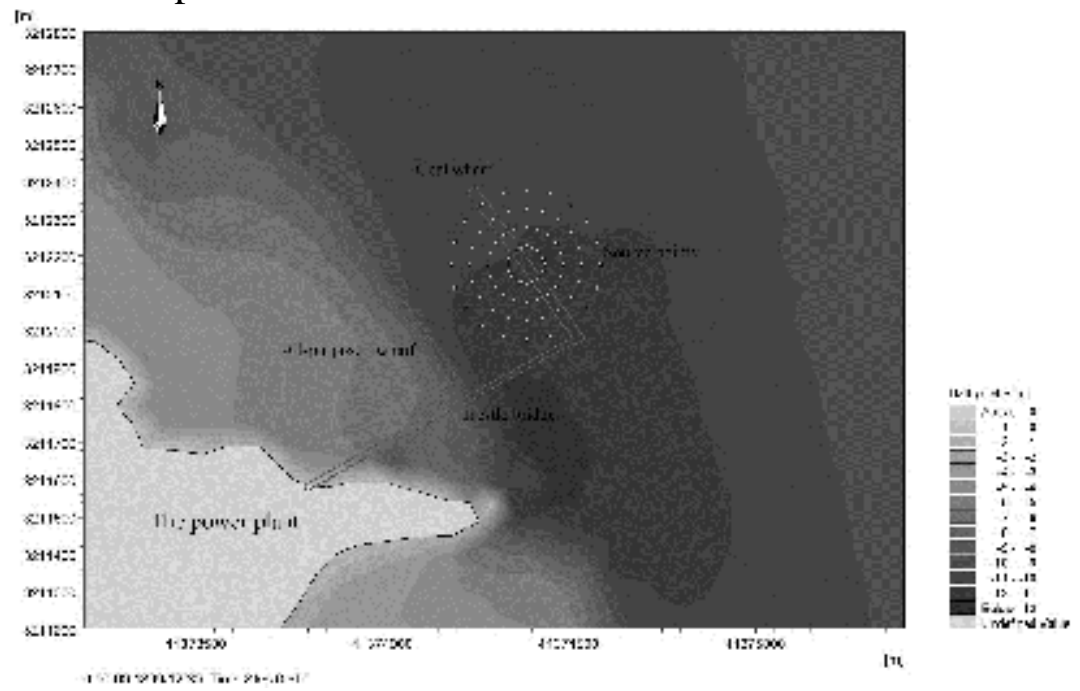

Fig.1 Sketch of the generalized points of coal dust source on the sea surface

The Settling Velocity of Coal Particle in Seawater. The settling velocity of the coal dust particle in the seawater can also be estimated by the Stokes settling velocity formula:

$$
\omega_{s}=\frac{g d^{2}\left(\rho_{m}-\rho_{w}\right)}{18 \mu}
$$

Where $\omega_{s}$ is the settling velocity of coal particle in seawater; $\rho_{m}$ is the density of coal $\left(\mathrm{kg} / \mathrm{m}^{3}\right) ; \rho_{w}$ is the density of seawater; $u$ is the dynamic viscosity of sweater.The settling velocity of different sizes can be calculated by Eq.12, and the result is shown in Tab.3. Settling velocity of different sizes are quite different, the smaller the particle size, the smaller settling velocity ,the longer the time suspended in the water.

The average depth at the front of the wharf is about $12 \mathrm{~m}$, so $0 \sim 40 \mu \mathrm{m}$ coal dust will sink onto the seabed in about 43 hours, $161 \sim 200 \mu \mathrm{m}$ coal dust will sink onto the seabed within 0.5 hours, the resuspension of the coal particles were not considered. The pollution source is divided into 5 parts, 0 $\sim 40 \mu \mathrm{m}, 41 \sim 80 \mu \mathrm{m}, 82 \sim 120 \mu \mathrm{m}, 121 \sim 160 \mu \mathrm{m}$ and $161 \sim 200 \mu \mathrm{m}$ represent five different particle size range of coal dust, all the separated result will be added to calculate the maximum envelope area of the concentration of suspended coal particles .

Table 3 settling velocity of coal particles in seawater with different sizes

\begin{tabular}{lll}
\hline Size range $(\mu \mathrm{m})$ & Characteristic size $(\mu \mathrm{m})$ & Settling velocity $(\mathrm{m} / \mathrm{s})$ \\
\hline $0 \sim 40$ & 20 & $7.84 * 10^{-5}$ \\
$41 \sim 80$ & 60 & $7.06^{*} 10^{-4}$ \\
$81 \sim 120$ & 100 & $1.96^{*} 10^{-3}$ \\
$121 \sim 160$ & 140 & $3.84 * 10^{-3}$ \\
$161 \sim 200$ & 180 & $6.35^{*} 10^{-3}$ \\
\hline
\end{tabular}

Mesh Setting. The domain of the numerical model is shown in Fig.2, the computational domain area is about $11939 \mathrm{~km}^{2}$. Unstructured triangular meshes is used in the model, in order to ensure the accuracy of the simulation, the mesh is as fine as $5 \mathrm{~m}$ at the region around the wharf. A flow field of 15 consecutive days which has been validated was used as the hydrodynamic condition, the unloading operation of coal in the wharf was assumed continuous, the model calculates 15 days to analyze the suspension of coal dust in seawater. 


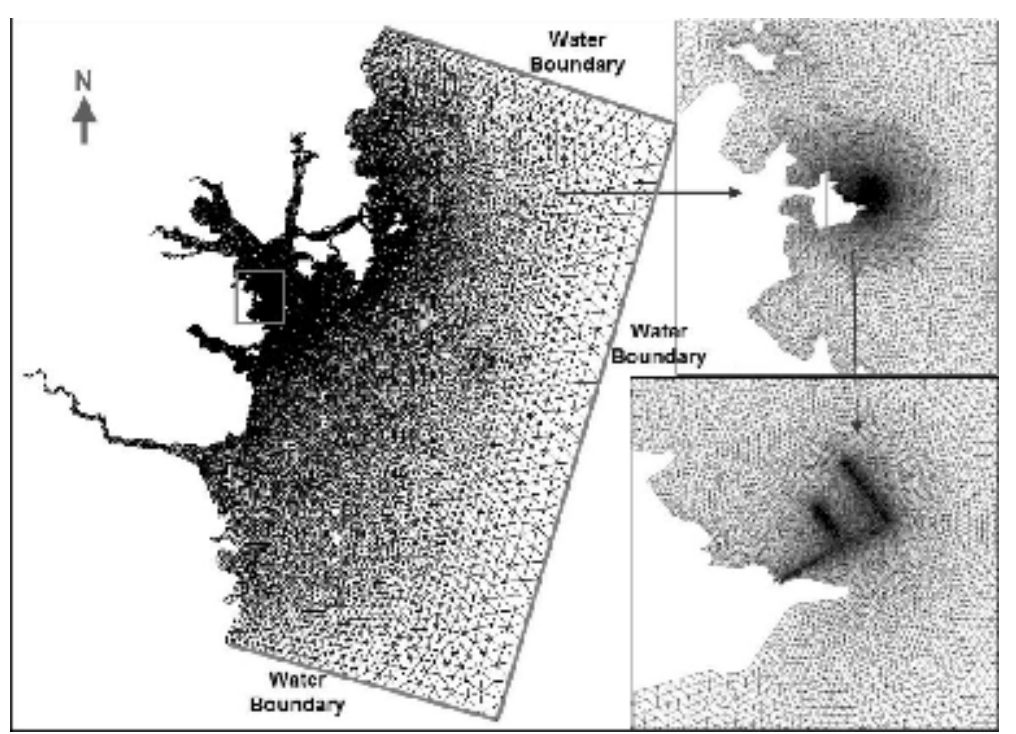

Figure 2 Sketch of computational region and mesh

Calculation Result. Due to the effect of flood and ebb tidal current, the coal dust that was suspended in seawater would be drifted along with the tidal current. The transport direction of the suspended particles was almost consistent with the direction of the tidal current. It was shown in Figure 3 that the concentration of suspended particles in seawater in the condition of the continuous unloading operation on the wharf, and statistics of the envelope areas of different concentrations levels was shown in Table 4.

Table 4 statistics of the envelope areas of concentrations levels of suspended coal particles

\begin{tabular}{llllll}
\hline concentration $(\mathrm{mg} / \mathrm{L})$ & $\geq 0.05$ & $\geq 0.10$ & $\geq 0.15$ & $\geq 0.20$ & $\geq 0.40$ \\
\hline Envelope area $\left(\mathrm{km}^{2}\right)$ & 0.405 & 0.102 & 0.053 & 0.032 & 0.007 \\
\hline
\end{tabular}

The diffusion range of the suspended particle was primarily limited to the region of about $1 \mathrm{~km}$ around the wharf .Because of the great efficiency of dust suppression device, the amount of coal dust that can drift into the sea surface was small, only $0.0193 \mathrm{~kg} / \mathrm{s}$, and the settling velocity of coal particles in seawater was comparatively fast. The envelope areas which have a concentration greater than $0.05 \mathrm{mg} / \mathrm{L} 、 0.1 \mathrm{mg} / \mathrm{L}$ and $0.2 \mathrm{mg} / \mathrm{L}$ were $0.405 \mathrm{~km} 2 、 0.102 \mathrm{~km} 2$ and $0.007 \mathrm{~km} 2$ respectively.

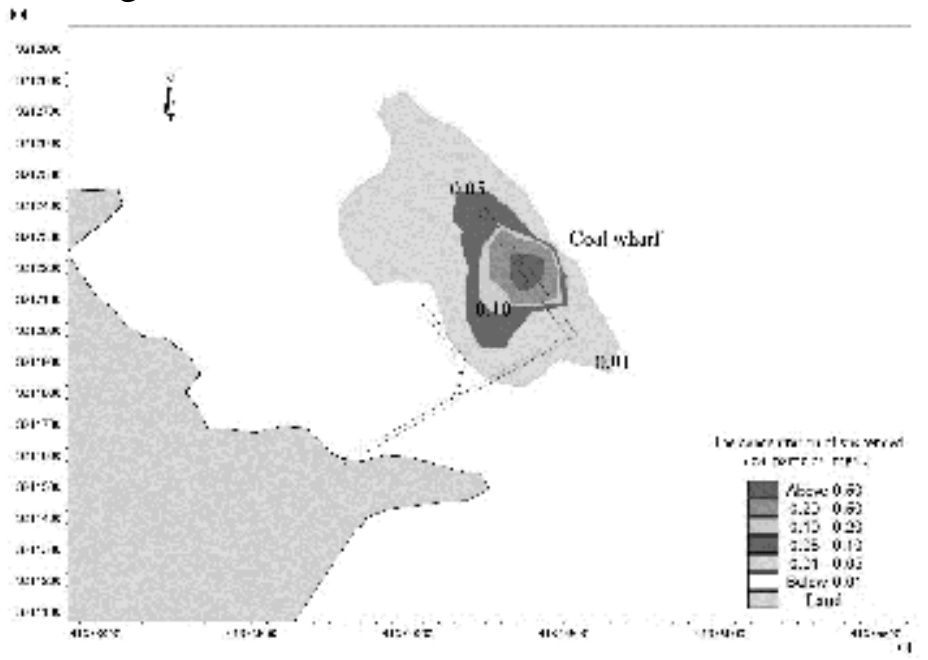

Fig.3 Envelope areas of concentration of suspended coal particles

\section{Conclusions}

The process of coal dust affect the marine environment was described as three steps: first of all drift down to the sea from the operation zone of the wharf, second suspended in seawater and drift along with tidal current and finally sunk onto the seabed under its own gravity. In the first step, a standardized formula was used to estimated the amount of raised coal dust that can drift into sea and 
the range of dust that reach the surface of sea was generalized as a circle through the Stokes formula and Walker's model. In the second step, a Lagrangian particle tracking method based on a 2-D hydrodynamic model was established to simulate the diffusion of suspended coal particles. Through this method the maximum possible suspension concentration of coal particle can be estimated, the result can be used to assess the impact of coal dust on the marine environment on the operation of coal wharf.

This paper was subsidized by Science and technology plan projects of Zhejiang province (2015F50064).

\section{References}

[1] National Bureau of Statistics:Statistical bulletin of the national economic and social development of the People's Republic of China in 2015.(2016)

[2]Wang Youqing, Liu Tie-ying:Atmospheric Depositing Dust and Its Total Amount Control of Coal Wharf, Environmental Protection in Transportation.No.5.(2002)

[3]Zeng Defang: Prevention and treatment of the dust polluting in coal wharf of our country, World Shipping.Vol.28,No.5.(2005)

[4]GB 50821-2012.Code for design of environmental protection in coal industry, Beijing: China Planning Press.(2012)

[5]Guo Shan,Zhan Shuifen,Zhang Binbin,Zhou:Jun,Review of dedust technique in coal harbor, Journal of Waterway and Harbour, Vol.27 No.1.(2006)

[6]DHI.2012. MIKE21 \&MIKE3 FLOW MODEL FM Hydrodynamic and Transport Module Scientific Documentation. (2012)

[7]DHI.2012. MIKE21\&MIKE3 FLOW MODEL FM Particle Tracking Module Scientific Documentation. (2012)

[8]Ma Guangda:Air pollution control engineering. Beijing: China Environmental Science Press.(1985)

[9] Li Zongkai, SUN Run-qiao: The principle and application of air pollution meteorology. Beijing: China Meteorological Press. (1985)

[10] Zhang Guanxin, Du Wancheng and Wen Wei-ying:Estimation of marine environment affected by coal dust of coal wharf in a power pant, Tropic Oceanology, Vol.14,No.4.(1995) 